\title{
Resource Integration in a Vehicle Ecosystem
}

\author{
Awatif Alotaibi \\ Queensland University of \\ Technology \\ 2 George Street \\ Brisbane QLD 4000, Australia \\ awatif.alotaibi@hdr.qut.edu.au
}

\author{
Alistair Barros \\ Queensland University of \\ Technology \\ 2 George Street \\ Brisbane QLD 4000, Australia \\ alistair.barros@qut.edu.au
}

\author{
Kenan Degirmenci \\ Queensland University of \\ Technology \\ 2 George Street \\ Brisbane QLD 4000, Australia \\ kenan.degirmenci@qut.edu.au
}

\begin{abstract}
Service-dominant logic has moved users from consumers to valued co-creators in transactional ecosystems. In service-dominant logic, privacy and trust are private resources. This logic is a metaperspective that needs to be integrated with mid-range theories to investigate how these resources are integrated, and what influence the integration. Thus, this study uses the enhanced antecedents-privacy concerns-outcomes model. This model includes different levels of cognitive effort that influence private resource integration. Then, we conducted interviews with Tesla owners in Australia. Tesla owners gave high-level cognitive responses and attitudes, including environmental concerns, altruism, attitudes towards electric vehicles and privacy concerns. They also gave low-level cognitive responses or biases, such as implicit trust and positivity. Specifically, our findings indicate that users distrust vehicle manufacturers; environmental concerns lead to perceived benefits; altruism, implicit trust and positivity mitigate privacy concerns; and privacy concerns increase the perceived privacy risks. These behavioural responses influence resource integration, feeding into our proposed model.
\end{abstract}

\section{Introduction}

Vehicles have traditionally been considered goods rather than 'mobility services'. However, vehicle marketing logic must move towards a service-dominant (S-D) paradigm [1] to reflect a progressive evolution, emphasising the role of customers as the co-creators of value [2]. In the quest for owner-derived satisfaction and driving experience, drivers will access state-of-the-art digital services, including in-vehicle entertainment, fast charge capabilities and ultimately self-driving vehicle autonomy. To optimise these benefits, vehicle manufacturers must overcome barriers to ensure resource integration by users.
One barrier to users is privacy. A Deloitte survey showed that most customers declined telematics services based on privacy concerns and distrust the service providers who wanted to monitor customer behaviour [3]. Specifically, $47 \%$ of respondents indicated definite rejection of the services, and $27 \%$ indicated they would agree if the prices were fair and a high discount was given. Thus, we argue that privacy and trust interactions negatively and positively affect value creation.

Today, users' expectations have changed. They desire more from vehicles than moving from points $A$ to B. A range of connected, autonomous, shared, electric (CASE) vehicles are emerging to suit these needs. Some people desire connected vehicles (CVs) with external wireless communication capabilities and various apps and services. Some desire autonomous vehicles (AVs) that perceive the surroundings, design routes and execute navigation. Shared vehicles (SVs) have also become available for those who prefer changeable tripbased costs over car ownership. Finally, electric vehicles (EVs) are desirable for those who prefer renewable energy over fuel consumption for environmental reasons. Manufacturers such as NIO, Lucid Motors and Tesla are responding to these user preferences.

To our best knowledge, Tesla is the only manufacturer to achieve this formula [4]. Tesla has the highest market value of all vehicle manufacturers [5]; however, it has experienced issues with clients over new vehicle delivery timelines, new technology such as full self-driving (FSD) and charging products. This might be partly due to a lack of policies or infrastructure to support the concept of CASE vehicles in many countries. For example, in Australia, the EV market has yet to mature, with electric vehicles accounting for only $0.6 \%$ of new vehicle sales [6].

There is little research into the vehicle ecosystem from an S-D logic perspective. One study found that ensuring privacy is considered an operant resource [7]. Personal data was considered an operant resource when 
the organisation utilised their capabilities for value proposition [8]. Moreover, privacy and trust have been proposed as private resources, charging infrastructure as public resources, and attitudes and bias as other components of institutions and institutional arrangements [9]. Our study investigates resource integration in the context of the vehicles ecosystem. This study answers the question: What are the resources, what influences resource integration and how?

\section{Background}

\subsection{S-D logic as metaperspective}

S-D logic is a metaperspective developed by Vargo and Lusch that argues that the aim of economic exchange, from the production and distribution of goods for sale to the exchange, is based on service [10]. 'Service' in S-D logic means applying resources, activities, processes and performance to benefit one or more actors [10]. S-D logic emphasises the benefits enjoyed by actors from the application of specialised knowledge and skills.

Resources can be operand and operant, the former often being tangible and static (e.g., natural resources), with the latter intangible and dynamic (e.g., skills, knowledge and technology) [11]. Operant resources are valuable, often dynamic, challenging to transfer and consequently a source of sustained competitive advantage. Resources need to be integrated with other resources to increase value. Many integrated resources are market-facing, but many are also non-market-facing, such as private resources (e.g., trust, knowledge) and public resources (e.g., societal institutions, public lands and infrastructure) [11].

The vehicle ecosystem consists of a loose, synergistic association between drivers and a range of support industries, social media interests, government departments and regulatory bodies. The value may be viewed as a cost-benefit relationship [12]. Value cocreation is a cooperative process of mutual value creation among different agencies [13]. The context of values are coordinated through institutions (e.g., among users) and institutional arrangements (e.g., among users and organisations), including norms, beliefs and attitudes [14]. The value is created through resource integration and value-in-context. This occurs when individuals and organisations exchange operant and operand resources [15].

\subsection{The enhanced APCO model as a mid-range theory}

Economic theory considers privacy as a tradable commodity [16]. Privacy calculus theory explains how users analyse risk and benefit in decision-making, and this calculus is influenced by privacy concerns [17]. Further, privacy calculus theory has been studied in the $\mathrm{CV}$ context, and its influence on CV adoption was significant $[18,19]$. An extension to the privacy calculus model, the enhanced antecedents-privacy concernsoutcomes (APCO) model, has been developed in determining deliberate behavioural responses as antecedents [20]. The APCO model has operationalised CV adoption [21], including privacy and trust. The concept of FSD, which relies on connectivity, raises privacy concerns and challenges [22].

Trust in the SV platforms helps to promote user adoption intention [23]. Other scholars have been inspired by the enhanced APCO model, which includes unintentional cognitive responses besides the deliberate cognitive responses and antecedents as factors that influence trust, privacy concerns and privacy calculus in the Tesla ecosystem [9].

The enhanced APCO model identifies two levels of cognitive responses. First, the high-level cognitive responses such as thinking are controlled, intentional and highly focused [24]. However, this form of cognition, typical of analytical, concentrating thinkers, requires significant effort, is time-consuming and temporally exclusive. As such, high-effort thinking may frame attitudes. Second, low-level social cognitive responses are classified as automatic, involuntary and requiring little effort. Low-effort thinking is helpful for daily life [24, 25], saving us time and effort and, as a background cognitive process, allows us to actively engage with higher cognitive tasks. However, such thinking can subconsciously lead us to false assumptions or biases.

\subsection{Theoretical approach}

The theoretical perspective is based on S-D logic and the enhanced APCO model that extended from [9] but focusing on high- and low-level cognitive responses. We aim to study the concept of resource integration in terms of resource types, the influence of the level of responses which is institutions and institutional arrangements from S-D logic, and how these resources are integrated. We emphasise the importance of this study because value creation only occurs when a potential resource is applied and contributes to a specific benefit [26]. Resource integration is 'a series of activities performed by an actor' [27]. These activities are coordinated by social institutions and institutional 
arrangements [28]. S-D logic has several foundational premises (FPs) [13], and at least three are fundamental to this paper. FP4 states that 'operant resources are the fundamental source of competitive advantage'; thus, we argue that privacy and trust are critical private resources influencing resource integration and value co-creation. FP6 states that 'the customer is always a co-creator of value'; thus, we limit our scope to study the users. FP 11 states that "value co-creation is coordinated through actor-generated institutions and institutional arrangements'; therefore, we argue that beliefs, norms, attitudes and biases coordinate resource integration.

\section{Methodology}

\subsection{Data collection}

Australian Tesla owners were chosen for this study for several reasons. First, the geographical distance from the US creates uncertainty around shipments, including costs and delivery. Moreover, The Australian Government does not provide notable support or incentives to encourage EV adoption, and it does not allow robot taxis or FSD software. Tesla insurance is not activated in Australia, which adds complications since insurance companies consider Tesla vehicles as luxury cars. Therefore, we found that Australian Tesla owners face uncertainty and barriers that deserved to be studied.

This paper studies Tesla as an exploratory, single case study [29]. Choosing Tesla as a single study is suitable as it is the only manufacturer in the top 15 companies on the sale market that provides the CASE vehicle concept. The study focuses on Tesla users as value creators and resource integrators from the S-D logic perspective and investigates the barriers they face.

Data were collected for this exploratory study through a series of 11 semi-structured qualitative interviews with Tesla car owners in Australia $(\mathrm{N}=20)$. We asked about their motivations, obstacles and how they evaluate their experiences. The interviews were conducted over six months (September 2020-February 2021) in English via Zoom online interviews lasting approximately 60 minutes and were recorded digitally and transcribed.

\subsection{Analysis}

Thematic analysis was used to analyse how the responses represented interviewees' perceptions, interpretations and factual understanding [30]. We used NVivo 12 to compile, analyse, and manually code data, following Braun and Clarke's six-step analytic process [30]. Data process coding was then completed inductively without fitting the data to a pre-existing coding frame. Step 1 involved iterative data reading to generate robust understanding. In step 2, author AA manually constructed initial codes. The 62 initial codes were extracted from interviewee responses. These data were coded explicitly or implicitly. For example, the statement 'I am conscious of the environment as well. It's good that it would be far more environmentally friendly than internal combustion engine cars as well' was coded as explicit for environmental concerns since they made this decision consciously. Implicitly, the statement that 'there's probably nothing wrong. It's just that you feel like you're, like big brother is watching you. At the same time, as I said, it is comforting to know that they can also diagnose anything that's wrong with your car remotely' was coded as positivity bias. In step 3 , author AA identified these themes twice. In step 4, both co-authors reviewed the thematic map to maintain internal homogeneity among codes while allowing for external heterogeneity between themes. The authors agreed on the validity of the themes, but minor modifications were made to the codes. In step 5, author AA re-read the dataset, coded all missing units, regrouped any outliers from earlier phases. The themes were revised, including final thematic definitions and names reflecting the theoretical perspective (see Table 1). The findings and discussion from step 6 are presented in Sections 4 and 5.

Table 1. Definition of themes

\begin{tabular}{ll}
\hline Theme & Definition \\
\hline $\begin{array}{l}\text { High-level } \\
\text { cognitive } \\
\text { response }\end{array}$ & $\begin{array}{l}\text { Deliberate economic and psychological } \\
\text { evaluation or specific attitudes } \\
\text { expressed by vehicle owners: This } \\
\text { includes environmental concerns, an } \\
\text { altruistic attitude towards full self-driving } \\
\text { capability and an attitude towards EVs } \\
\text { and privacy concerns. }\end{array}$ \\
$\begin{array}{l}\text { Low-level } \\
\text { cognitive }\end{array}$ & $\begin{array}{l}\text { Unintentional and } \\
\text { response } \\
\text { bias enacted by vehicle owners. } \\
\text { concern }\end{array}$ \\
& $\begin{array}{l}\text { The process of private resource } \\
\text { integration: Private resources (privacy } \\
\text { and trust) are integrated during privacy } \\
\text { calculus/resource integration. }\end{array}$ \\
\hline
\end{tabular}

\section{Findings}

Three main themes emerged from the thematic analysis, namely, high-level cognitive response (HLCR), low-level cognitive response (LLCR) and privacy concern (PC). HLCR includes environmental concerns, an altruistic attitude towards self-driving capability, and several concerns about EVs. LLCR includes implicit trust and positivity biases. Finally, PC 
include privacy concerns, trust and privacy calculus that mediate privacy risks and perceived benefits. Quotations throughout the following thematic results are attributed to the participants according to their participant number (e.g., $\mathrm{P} 1=$ participant 1$)$.

\subsection{Theme 1. HLCR}

Environmental concerns. Participants had environmental concerns, and EV adoption was viewed as significant in protecting the environment: 'I have got to buy one of these, even though it was ridiculously out of reach in my price range. But it was mainly for environmental reasons and supporting the concept of electric vehicles. Certainly not value for money' (P13, p. 1). Some participants consciously decided to reduce pollution: 'I am conscious of the environment as well. It's good that it would be far more environmentally friendly than internal combustion engine cars as well' (P7, p. 1). This reflects an underlying imperative for change; for example, 'moving away from a fossil-fuelled vehicle to me was important simply to say we need to move to an alternate transport paradigm' (P2, p. 3).

Altruistic attitudes towards FSD capability. EV owners expressed altruistic, supportive attitudes towards FSD capability that overrode concerns regarding private data sharing. One participant explained, 'I think, [we] are very happy with that because it all helps to improve the software, especially with things like the full self-driving package' (P4, p. 6).

Attitude towards EVs. The attitude towards EVs is formed by conscious, rational consideration of price, value, range confidence, technical design and service as factors in adopting EVs.

Regarding price value, some participants stated that EVs are not affordable: 'the car that I've got, it's a luxury that I'm fortunate that I can afford, but I'm an oldie, I can afford it, and I don't think there's too many young people that can afford to buy the more expensive car' (P8, p. 2). Another participant explained: 'they don't seem to give any clear indication around the cost of anything in advance' (P6, p. 8). However, EV owners were optimistic: 'once you factor in hopefully some good depreciation there, good quality, low depreciation. It should be pretty good' (P12, p. 1). Others attributed the high price to shipment costs: 'I am fairly sure it's a lot more expensive to buy a Tesla compared to in the US because that's where they have their factories or in China, for example, as well ... there is always going to be important expenses' (P7, p. 6). Another participant commented on the lack of Australian government support: 'so, when it comes into Australia, we get hit with all sorts of things like luxury car tax and goods and services tax' (P8, p. 9). This was supported by P16: 'Victoria charges one of the highest stamp duties, so we had to pay $\$ 5000$ on this car. It is now, in Victoria, $\$ 6000$ for a new Tesla. There is no incentive to buy. It is one of the reasons why they are so expensive. We get slugged all over the place' (p. 24).

Range confidence. A suboptimal charging stations network was a concern for participants: 'I just reached anxieties. To say that although the Tesla superchargers are available every 150 kilometres, of course, it is not like a petrol station that along the way ... you really have to plan your trips very well' (P12, p. 5). Charging time was also of concern: 'well, now you need to wait for, seriously, up to an hour while the people who are completely charging the battery or whatever, finish before you even get a look in ... then you need to maybe charge for an hour. That turns an experience that you get in a petrol station, [which] is like a five-minute wait, into like a two-hour, can potentially be longer scenario' (P5, p. 18). The need for improved infrastructure was also identified: 'the charging infrastructure element is the most frustrating element of owning an electric car right now. There are still very limited, in Queensland, there are still very limited fast-charging stations around' (P5, p. 15). Others agreed: 'until superchargers and destination chargers are ubiquitous, I see EV's being off the agenda for many motorists' (P8, p. 2). However, improvements in Tesla's battery technology were recognised: 'I did a lot of research on the battery technology in the Tesla, and I found out these Tesla are really good in terms of the battery technology and they last forever' (P14, p. 6).

Service concerns. One participant was concerned because car manufacturers alter business terms with car owners, such as the warranty period: 'it's not clear from their current website what actually the warranty is for a car from 2014. So, you can see what the current warranty is, but you can't actually see what conditions were regarding the warranty on a car from 2014' (P6, p. 7). P11 believed the warranty was limited: 'the warranty's not great. It is four years, it is only 80,000 kilometres, it's not a lot. I know people that actually run the warranty out in just over a year centrally, because they've driven so many kilometres' (P11, p. 8). Another suggested that the quality of services has been reduced: 'it was eight years unlimited kilometres on the vehicle, and the battery, and the drive train. And then they've, I think altered that warranty as they've gone along' (P13, p. 3). Another participant was concerned because service delivery was not always on time: 'I bought the car in 2015. We did not actually get [it], because of lots of things that happened with getting things from the US to here, we got our Tesla batteries in February 2018' (P16, p. 5). 


\subsection{Theme 2. LLCR}

Implicit trust. Tesla owners tended to assume the honesty of Tesla: 'Tesla has very clear policies that they will not sell my personal data to any companies, any third parties. That is why I trust Tesla' (P14, p. 8). Owners assumed Tesla would not breach trust unless they became aware of privacy breaches: 'I think that company would be trusted. I mean, you hope that that's the case, right, until you hear something and then it means like, "oh, yes," like, "someone has hacked into that company"' (P17, p. 15). Some participants trusted EV manufacturers automatically: 'I think privacy is a big issue, but when you buy a product, you kind of have trust, automatic trust because everything is digital. We use credit cards, and we are not completely detached from the electronic economy today' (P17, p. 15).

Positivity bias. Participants indicated that EV owners were loyal to Tesla: 'Tesla drivers are very positive about their experience ... Tesla takes a great deal of care to make sure that the experience that people have when they drive or buy those cars is a positive experience' (P1, p. 4). It was also suggested that Tesla owners preferred Tesla cars: 'the same reason people appreciate Apple is the reason to appreciate Tesla; [it] is that it's a defined, underlying experience instead of being a toaster with four wheels' (P5, p. 12). Participants were positive towards Tesla despite the EV manufacturer having access to significant amounts of personal data: 'There's probably nothing wrong. It's just that you feel like you're, like big brother is watching you. At the same time, as I said, it is comforting to know that they can also diagnose anything that's wrong with your car remotely' (P5, p. 12).

\subsection{Theme 3. Privacy concern}

Privacy concerns were conceptualised as multidimensional, including perceived surveillance, data transfer to international organisations and personal data erasure or deletion.

Perceived surveillance. Participants believed that the location of the EV is monitored, at least part of the time: 'I must admit, I suppose the one thing that I'm not entirely happy about with all of that information is our location information is always available' (P2, p. 5). Further concerns suggested that FSD capability may collect too much information: 'they know my altitude, my location, my speed, the temperature inside, the temperature outside, the battery charge. So, it's very extensive what they know' (P20, p. 2). As expressed by P5, the FSD capability may monitor the activities of EV users: 'Tesla themselves [have] my driving data, so you know they can track the disengagements with autopilot' (P5, p. 6).
External storage. Concerns were raised regarding external data storage: 'most of the data [that] have been used today is mainly stored in the US' (P3, p. 2). The same participant also stated that 'there are data centres in Europe, Asia and Australia. Nevertheless, the possibilities of errors are high because these are very often just backup systems and have redundant data', and 'there is [a] possibility of unauthorised access' (P3, p. 2). Importantly, the computers in EV cars were also a cause for concern: 'I don't trust them enough to be comfortable giving them the old computers in my car when they have to replace it, and they say they have to keep the old computer. No, I don't trust them, because I don't believe that Tesla, or any other large commercial enterprise, is really that familiar with cybersecurity' (P1, p. 3).

Personal data erasure. A participant raised concerns regarding the purchase of a second-hand EV: 'I think, in terms of his [the previous owner's] personal data in the maps of the Tesla, there was his history, so, all the locations he'd put into the address book were there. It might have had his contacts that were on his phone by people that he rang, that might have been on there. But the Tesla app, he signed that over to me, so basically, when I took ownership of the car, he removed himself from it, and then added me, and I received confirmation from Tesla that that went through. But it definitely didn't erase his map history, or any of that off the computer in the car' (P15, p. 3). EV owners did not know how to delete the personal data from the EV: 'to be honest, I've got no idea what would happen. I'm not sure if they delete that' (P9, p. 5). One owner was concerned that the manufacturer would not remove his personal data: 'Tesla should take the responsibility to do that [remove the seller's personal data]. However, Tesla given they like to call themselves [a] technical company, so they should be well on top of privacy, and apps, and all that sort of stuff' (P15, p. 4).

Trust in service provision was conceptualised as a multidimensional construct, including integrity, benevolence and ability.

Integrity. One of the participants did not expect the EV manufacturer to keep their promises: 'I' $m$ really not confident, to be honest, in Tesla's service because they keep on doing things that make me nervous as an owner. So, things like changing the warranty times -length of duration in their used cars-it is all being reduced from four years or two years down to one year' (P6, p. 8).

Benevolence. One participant perceived benevolence: '[I] liked what Elon Musk's approach is to the environment, and he says he's trying to better the human race, and I think he genuinely believes that' (P13, p. 2).

Ability. Another participant believed that EV manufacturers provided reliable cars: 'I think I am pretty 
comfortable, probably more because I am an engineer, so I have a bit more of an understanding of how cars work, and how batteries work, and how reliable they are. Like, I have a reasonable amount of confidence. I think they are committed, especially, I have got some confidence now that Tesla, I believe, have been profitable for about six quarters in a row ... I think they are pretty well established' (P14, p. 8).

Privacy risks. EV owners anticipated 'the risks of political and industrial preferences' (P3, p. 5), specifically that the Tesla and related third-party applications may 'control, open the car, close it, turn it on, but I believe this is so risky. I think it is so risky to give this authority to [a] third-party app. I will be okay if it is [a] Tesla app. It is okay for me, but to the third party, I think that is kind of risky' (P10, p. 35). Another participant explained that 'they know exactly what car I have, and the vehicle identification number and everything. So, I am sure they are collecting a lot of information I do not know about. Well, Tesla does this as part of the whole ecosystem; they collect data from all the cars, all the time, in real-time. And that gets fed back to Tesla headquarters. So, there is a lot of data being shared by me unknowingly' (P4, p. 2). P20 also stated that 'the downside is I would rather not have that information publicly available' (p. 2).

Perceived benefits. Tesla EV has unique perceived benefits through the application of new approaches to EV connectivity and autonomy.

Perceived environmental performance. One participant indicated that 'the benefit of electric vehicles are no emissions. In a way that is not quite correct, because somewhere you are still burning coal to create electricity, but potentially, you could have ... like if we had solar panels on our roof, enough solar panels on our roof, we could charge our car from the solar panels. So effectively there are no emissions from the car' (P19, p. 8).

Perceived connectivity benefit. EV owners perceived reliability benefits: 'so if you do have an issue, you can contact them via the car, via the touch screen' (P9, p. 2). The perceived benefits also included enhanced safety with the autopilot capabilities: 'it is more aware than most drivers, so I feel safer in the car, the car driving, than I do watching other cars manoeuvre around me. When it's on automated pilot, it sits in the centre of the lane. It doesn't move from side to side. Even if there's wind, it'll move momentarily and then will re-centre itself. So, I feel a lot safer with it, and a lot less stressed. Driving now is less stressful going to work' (P10, p. 19). One participant noted the entertainment benefits: 'I' $m$ absolutely enjoying the innovation that it brings to cars. We've been enjoying using Netflix. You can just sit at the charger and watch Netflix, which is just crazy' (P7, p. 5).

\section{Discussion}

Operant resources are highly valuable, often dynamic and difficult to transfer. Therefore, they are a useful source of sustained competitive advantage [31]. Thus, S-D logic leverages the application of knowledge to benefit stakeholders. This paper argues that privacy and trust are significant, non-market-facing operant resources. Institutions and institutional arrangements coordinate and shape users' evaluations. This coordination leads to several beliefs, attitudes and biases [31]. In this discussion, we operationalise the constructs and their relationships from the enhanced APCO model as a mid-range theory and answer the research question from an S-D logic perspective.

\subsection{Institutional arrangements}

Environmental concerns are defined as EV owner's awareness of environmental challenges and their support and personal contribution to environmental solutions [32]. Previous work has discussed how new, environmentally sensitive vehicle technologies may influence customer decisions [33]. This paper shows that EV owners are concerned with, and committed to, environmental protection [34].

Altruism is an important aspect of knowledge sharing [35, 36]. In this paper, altruism is defined as vehicle owners' willingness to share their private data to help improve FSD capabilities [37]. Tesla owners were happy to share their personal information to use FSD capability. They explained that this sharing is important for enhancing the technology.

Attitudes towards EV define the degree to which $\mathrm{EV}$ adoption is positively or negatively valued [38]. The price value is the consumers' cognitive trade-off between the perceived benefits of the EV and related services and the cost for using it. EV users expressed concerns regarding the total cost of EVs because of the high price of Tesla vehicles and because Tesla does not specify the total cost.

Range confidence involves the EV user's experience of the EV range, their knowledge of battery technology improvements and charging infrastructure availability [39]. Participants were concerned with the charging infrastructure and range capabilities of EVs. This is consistent with a 2020 survey where $45 \%$ of participants said these factors discouraged them from purchasing an EV [6]. Conversely, 58\% disagreed; for example, 'infrastructure is not a concern, I know I can charge at home' [40, p 28.].

Service concern was defined as Tesla owners' evaluations of the EV services that they received. One concern was that EV manufacturers provide unreliable and limited warranties, reduce their service quality and 
delay service delivery time. Despite difficulties estimating the total cost of EVs [8], Tesla exacerbates this situation by changing its terms and conditions. In the public domain [35], Tesla has reduced the warranty period for used vehicles from four years to one year, leading to uncertainty about warranty terms. The new warranty terms are significantly less beneficial to consumers buying used EVs directly from Tesla.

Privacy concerns were associated with users' subjective perception of fairness in handling their personal data [41]. Internet privacy concerns have been studied as a multidimensional construct comprising collection, errors, secondary use and unauthorised access to information [42]. Further research identified mobile privacy concerns as perceived surveillance, intrusion and secondary use of personal information [43].

Because Tesla is a specific ecosystem, it has unique privacy concerns, risks and benefits. Tesla owners' privacy concerns can be classified into three main dimensions: perceived surveillance, external storage and personal data erasure. Perceived surveillance describes the tracking and profiling of EV users through EV technology capabilities [43]. These capabilities require transmitting vast amounts of private data, such as location, driving behaviour and vehicles identification, into an onboard computer [44]. Participants expressed their concerns as such critical information are revealed. External storage is defined as a transfer of personal data to an international organisation [45]. In Europe, the General Data Protection Regulation gives users absolute control of their personal data [45]. These data are protected by law, assuming the law is applied. The US and other countries must comply with these laws if they wish to store data. However, a participant was aware that most external data are stored in the US and separate data centres in Europe, Asia and Australia. This increases the chance of errors and opportunities for unauthorised access. Therefore, it is challenging to ensure lawful data control or accountability.

Personal data erasure is defined as the right to erase personal data once EV owners sell their vehicles as second-hand vehicles. Concerns arose as there are no clear instructions for erasing personal data, and some EV owners who bought second-hand vehicles found the previous owner's personal data [45]. Further, personal data stored in a vehicle computer that is replaced has an unclear destiny. These are privacy challenges confronting the vehicle services ecosystem. Nonetheless, some vehicle owners enjoy the benefits of current arrangements, preferring not to argue against them.

In contrast, implicit trust is defined as the absence of opposing information [46]. In this study, Tesla owners predominantly assumed that vehicle manufacturers are honest, based on the Tesla website's corporate vision and mission statements [47]. The manufacturer expresses corporate goals of connectivity and sustainability. These motherhood statements discourage Tesla users from analysing enterprise policies to identify unclear language or policy positions. Unless Tesla owners become aware of compromises to their trust, they tend to trust the company's statements regarding personal data [24]. Positivity bias is defined as Tesla owners' evaluation based on loyalty and preference despite a possible negative rational evaluation or perception towards privacy [24]. Tesla owners have loyalty to Tesla brand because they had positive experience, and they honour the brand as it expresses their preferences in the car choices even though the huge amount of data have been collected.

\subsection{Private resources}

Trust is defined as the intention to be vulnerable based on positive anticipation [48]. Trust has been conceptualised as a composite of ability, benevolence and integrity. Ability refers to $\mathrm{EV}$ owner beliefs regarding Tesla's capability to provide its services. Benevolence measures the degree to which Tesla is anticipated to have good intentions, separate from profit-seeking. Integrity reflects the extent to which Tesla is expected to adhere to its commitments and responsibilities in providing its services [48]. Our findings show that participants believed in the ability and benevolence of Tesla but not in its integrity to provide the services properly. Moreover, our data revealed that trust related to service rather than privacy.

Information privacy is the information that is personally identifiable or describes an individual's personal information spheres [49]. It is viewed as a commodity that can be traded [16]. Therefore, privacy is no longer considered an absolute social value but rather part of a cost-benefit analysis of individuals or groups [17]. As a result, we addressed how resources are integrated.

\subsection{How resources are integrated}

Privacy calculus theory in the vehicle ecosystem suggests resource integration has taken place when an EV owner compares privacy risks with perceived benefits, with the analytical result determining the values that would be created or abolished [17]. Privacy risks in an $\mathrm{EV}$ ecosystem are defined as the degree to which an EV owner believes that a high potential for loss is associated with releasing personal information to the EV manufacturer, service providers or being used for services in the Internet of Things [41, 50]. Thus far, information systems researchers have considered 
privacy risks a crucial construct in privacy calculus $[17$, 51]. In this study, participants identified a range of risks, including private data sharing in favour of influencing citizens and supporting certain industry areas, disclosure of data to third parties, remote vehicle control, potential loss during data transfer data and data being made public $[51,52]$.

Perceived benefits are defined as cognitive attractions to EVs that override privacy concerns. This occurs when EV owners exchange services with other resources, thereby generating benefits that outweigh privacy concerns [17]. EVs contribute to environmental sustainability, reduce environmental pollution and are important for preserving natural resources [39]. Perceived beneficial functions include enhanced invehicle entertainment services and the integration of personal devices and security and traffic control systems [21]. Tesla owners perceived these benefits in pursuing the values of transportation sustainability.

Relationships explain how resources are integrated. This exploratory paper found that environmental concerns influence perceived benefits. The shared belief in transportation sustainability among users and vehicle manufacturers makes users more aware of the benefits of using Tesla vehicles and, thus, promote wider Tesla vehicle adoption. We argue that those with environmental concerns can perceive the environmental and connectivity benefits and how these contribute to environmental sustainability. Despite the paucity of research discussing the association between altruism and privacy concerns, our inductive analysis suggests that altruism mitigates EV users' privacy concerns. Most participants voluntarily and consciously expose their personal data because they are aware of improving autopilot functionality, thereby increasing road safety. Thus, we argue that this change affects EV owners' trust towards EV manufacturers.

We suggest that other attitudes towards EVs influence trust in the manufacturer's service provision. This argument resulted from the participants' uncertainty of the cost, their range anxiety, concerns about terms and warranties being changed or limited, uncertain delivery services and reduced service quality. These concerns would lead users to distrust vehicle manufacturers.

However, participants implicitly trusted and were positive about using their vehicles and sharing their personal data. This bias resulted from positive experiences and the absence of breaches or incidents. One participant highlighted that implicit trust (as he referred as an automatic trust) because we rely on digital transactions in daily life, so there is no reason to exclude Tesla vehicles from this reasoning. Thus, we argue that EV owners' implicit trust and positivity bias negatively influence privacy concerns, as proposed by [24].
Participants highlighted privacy concerns about using their vehicles. These concerns included perceived surveillance, external storage and personal data erasure. From the subjective user evaluations, it is clear that participants understood risks associated with third parties sharing their private data, the vehicle being controlled remotely, losing data during transfers and data being made publicly available. Thus, we argue that privacy concerns positively influence privacy risks, consistent with [24, 41, 52].

\section{Contributions}

This study explored resource integration in vehicle ecosystems. It investigated private resources, the influence of institutions on resources and how these resources are integrated. A recently proposed model [9] integrated S-D logic and an enhanced APCO model. Consequently, we developed a construct model that focuses on private resource integration in vehicle ecosystems in depth. Our model produced the three themes that harmonised the broad theoretical perspectives (see Figure 1).

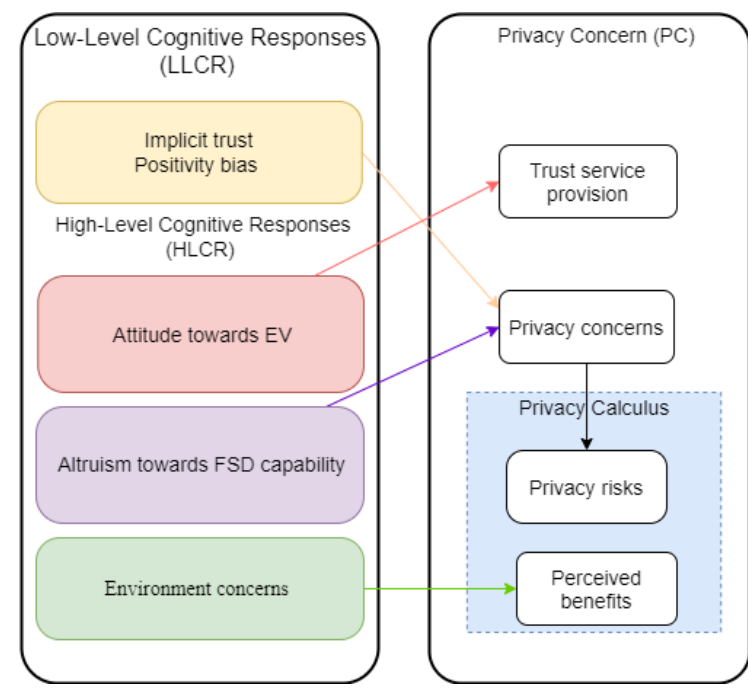

Figure 1. Construct model

This study informs vehicle manufacturers and service providers in a practical sense to understand the barriers faced by users. These barriers are shaped their behaviours and their adoption of vehicles and related devices and services.

\section{Limitations and conclusion}

S-D logic is an enormous theory that focuses on resource integration, interaction, value creation and service systems. This study focused on resource 
integration, but further research is suggested to investigate value creation such as transportation sustainability. Importantly, this work should be extended to other brands and countries for generalisability. Quantitative research can also be conducted to validate the results of this exploratory study [53].

In conclusion, S-D logic supports researchers to integrate mid-range theories for marketing and business. The enhanced APCO model was adapted to investigate the resource integration in a Tesla ecosystem case study. We conducted and analysed interviews with Tesla owners as value creators and resource integrators. We developed a construct model that illustrates privacy and trust as resources. We also identified cognitive influences as another component of social institutions in resource integration and how the resources have been integrated in terms of privacy calculus and relationships between constructs.

\section{References}

[1] C. Donada, "Electric mobility calls for new strategic tools and paradigm for automakers," International Journal of Automotive Technology and Management, vol. 13, no. 2, pp. 167-182, 2013.

[2] J. W. Lang, B. Reber, and H. Aldori, "How Tesla created advantages in the ev automotive paradigm, through an integrated business model of value capture and value creation," Business \& Management Studies: An International Journal, vol. 9, pp. 385-404, 2021.

[3] S. Friedman and M. Canaan. (2014). Overcoming Speed Bumps on the Road to Telematics: Challenges and Opportunities Facing Auto Insurers with and without Usage-Based Programs. Deloitte. Available: https://www2.deloitte.com/us/en/insights/industry/insura nce/telematics-in-auto-insurance.html

[4] D. J. Teece, "Tesla and the reshaping of the auto industry," Management and Organization Review, vol. 14, pp. 501$512,2018$.

[5] statista. (2021). Most Valuable Brands within the Automotive Sector Worldwide as of 2021, by Brand Value. $\quad$ Available: https://www.statista.com/statistics/267830/brand-valuesof-the-top-10-most-valuable-car-brands/

[6] Electric Vehicle Council, "State of electric vehicles," 2020. Available:

https://electricvehiclecouncil.com.au/wpcontent/uploads/2020/08/EVC-State-of-EVs-2020report.pdf

[7] T. Schulz, M. Böhm, H. Gewald, and H. Krcmar, "Doorto-door mobility integrators as keystone organizations of smart ecosystem: Resources and value co-creation-A literature review," presented at the 14th International Conference on Wirtschaftsinformatik, Siegen, Germany, 24-27 February, 2019.

[8] M. Mikusz and T. Herter, "How do consumers evaluate value propositions of connected car services?" presented at the 22nd Americas Conference on Information Systems, San Diego, US, 2016.

[9] A. K. B. Alotaibi, A. Barros, and K. Degirmenci, "Private and public resources information integration in electric vehicle ecosystem," presented at the 25th Pacific Asia Conference on Information Systems (PACIS), Dubai, UAE, 2021.

[10] S. L. Vargo and R. F. Lusch, "Evolving to a new dominant logic for marketing," Journal of Marketing Management, vol. 68 , pp. 1-17, 2004.

[11] R. F. Lusch and S. Nambisan, "Service innovation: A service-dominant logic perspective," MIS Quarterly, vol. 39, pp. 155-176, 2015.

[12] C. Grönroos, "Value co-creation in service logic: A critical analysis," Marketing Theory, vol. 11, pp. 279301, 2011.

[13] S. L. Vargo and R. F. Lusch, "Service-dominant logic: Continuing the evolution," Journal of the Academy of Marketing Science, vol. 36, pp. 1-10, 2008.

[14] S. L. Vargo and R. F. Lusch, "Service-dominant logic 2025," International Journal of Research in Marketing, vol. 34, pp. 46-67, 2017.

[15] S. L. Vargo and R. F. Lusch, "It's all B2B ... and beyond: Toward a systems perspective of the market," Industrial Marketing Management, vol. 40, pp. 181-187, 2011.

[16] S. Spiekermann, A. Acquisti, R. Böhme, and K.-L. Hui, "The challenges of personal data markets and privacy," Electronic Markets, vol. 25, pp. 161-167, 2015.

[17] T. Dinev and P. Hart, "An extended privacy calculus model for e-commerce transactions," Information Systems Research, vol. 17, pp. 61-80, 2006.

[18] M. Ju and J. Mou, "Privacy as a commodity is not the case: Privacy calculus model for connected cars," presented at the Wuhan International Conference on $e$ Business, 30 June, 2018.

[19] P. Cichy, T.-O. Salge, and R. Kohli, "Extending the privacy calculus: The role of psychological ownership," presented at the 35th International Conference on Information Systems, Auckland, NZ, 2014.

[20] H. J. Smith, T. Dinev, and H. Xu, "Information privacy research: An interdisciplinary review," MIS Quarterly, vol. 35, pp. 989-1016, 2011.

[21] C. Buck and R. Reith, "Privacy on the road? Evaluating German consumers' intention to use connected cars," International Journal of Automotive Technology and Management, vol. 20, pp. 297-318, 2020.

[22] S. Herrnleben et al., "Towards adaptive car-to-cloud communication," in 2019 IEEE International Conference on Pervasive Computing and Communications Workshops (PerCom Workshops), 2019, pp. 119-124.

[23] Z. Shao and H. Yin, "Trust building in the car-sharing platform: An empirical study in China," in International Conference on Information Resources Management (CONF-IRM), Ningbo, China, 2018.

[24] T. Dinev, A. R. McConnell, and H. J. Smith, "Research commentary-Informing privacy research through information systems, psychology, and behavioral economics: Thinking outside the 'APCO' box," Information Systems Research, vol. 26, pp. 639-655, 2015. 
[25] R. E. Petty, Attitudes and Persuasion: Classic and Contemporary Approaches. New York: Routledge, 2018.

[26] R. F. Lusch and S. L. Vargo, "The service-dominant mindset," in Service Science, Management and Engineering Education for the 21st Century, B. Hefley, W. Murphy, and W. E. Hefley, Eds. Germany: Springer, 2008, pp. 89-96.

[27] A. F. Payne, K. Storbacka, and P. Frow, "Managing the co-creation of value," Journal of the Academy of Marketing Science, vol. 36, pp. 83-96, 2008.

[28] I. O. Karpen and M. Kleinaltenkamp, "Coordinating resource integration and value cocreation through institutional arrangements: A phenomenological perspective," in The SAGE Handbook of ServiceDominant Logic, R. F. Lusch and S. L. Vargo, Eds. SAGE Publications, 2018, p. 284.

[29] R. K. Yin, Case Study Research: Design and Methods, 4th ed. SAGE Publications, 2009.

[30] V. Braun and V. Clarke, "Using thematic analysis in psychology," Qualitative Research in Psychology, vol. 3, pp. 77-101, 2006.

[31] R. F. Lusch and S. Nambisan, "Service innovation: A service-dominant logic perspective," MIS Quarterly, vol. 39, pp. 155-176, 2015.

[32] Y.-N. Sang and H. A. Bekhet, "Modelling electric vehicle usage intentions: An empirical study in Malaysia," Journal of Cleaner Production, vol. 92, pp. 75-83, 2015.

[33] G. Schuitema, J. Anable, S. Skippon, and N. Kinnear, "The role of instrumental, hedonic and symbolic attributes in the intention to adopt electric vehicles," Transportation Research Part A: Policy and Practice, vol. 48, pp. 39-49, 2013.

[34] N. Adnan, S. M. Nordin, M. H. Amini, N. Langove, and Practice, "What make consumer sign up to PHEVs? Predicting Malaysian consumer behavior in adoption of PHEVs," Journal of Cleaner Production, vol. 113, pp. 259-278, 2018.

[35] M. M. Wasko and S. Faraj, "Why should I share? Examining social capital and knowledge contribution in electronic networks of practice," MIS Quarterly, vol. 29, pp. 35-57, 2005.

[36] D. Constant, S. Kiesler, and L. Sproull, "What's mine is ours, or is it? A study of attitudes about information sharing," Information Systems Research, vol. 5, pp. 400421, 1994.

[37] M. Spann, O. Hinz, I.-H. Hann, and B. Skiera, "Decision making in virtual worlds: An experimental test of altruism, fairness and presence," in 18th European Conference on Information Systems, 2010.

[38] E. Heinen, K. Maat, and B. Van Wee, "The role of attitudes toward characteristics of bicycle commuting on the choice to cycle to work over various distances," Transportation Research Part D: Transport and Environment, vol. 16, pp. 102-109, 2011.

[39] K. Degirmenci and M. H. Breitner, "Consumer purchase intentions for electric vehicles: Is green more important than price and range?" Transportation Research Part D: Transport and Environment, vol. 51, pp. 250-260, 2017.

[40] Electric Vehicle Council, "State of electric vehicles," 2019.

Available:
content/uploads/2019/09/State-of-EVs-in-Australia2019.pdf

[41] N. Malhotra, S. Kim, and J. Agarwal, "Internet users' information privacy concerns (IUIPC): The construct, the scale, and a causal model," Information Systems Research, vol. 15, pp. 336-355, 2004.

[42] H. Smith, S. Milberg, and S. Burke, "Information privacy: Measuring individuals' concerns about organizational practices," MIS Quarterly, vol. 20, p. 167, 1996.

[43] H. Xu, S. Gupta, M. B. Rosson, and J. M. Carroll, "Measuring mobile users' concerns for information privacy," presented at the 33rd International Conference on Information Systems, Orlando, US, 2012.

[44] Tesla. (2021). Future of Driving. Available: https://www.tesla.com/en_AU/autopilot?redirect=no

[45] P. Voigt, The EU General Data Protection Regulation $(G D P R):$ A Practical Guide. Cham, Switzerland: Springer, 2017.

[46] D. T. Gilbert, "How mental systems believe," The American Psychologist, vol. 46, pp. 107-119, 1991.

[47] W. B. Dodds, K. B. Monroe, and D. Grewal, "Effects of price, brand, and store information on buyers' product evaluations," Journal of Marketing Research, vol. 28, pp. 307-319, 1991.

[48] R. C. Mayer, J. H. Davis, and F. D. Schoorman, "An integrative model of organizational trust," The Academy of Management Review, vol. 20, pp. 709-734, 1995.

[49] H. J. Smith, T. Dinev, and H. Xu, "Information privacy research: An interdisciplinary review," MIS Quarterly, vol. 35, no. 4, pp. 989-1015, 2011.

[50] M. S. Featherman and P. A. Pavlou, "Predicting eservices adoption: A perceived risk facets perspective," International Journal of Human-Computer Studies, vol. 59, pp. 451-474, 2003.

[51] H. Xu, H. H. Teo, B. C. Y. Tan, and R. Agarwal, "The role of push-pull technology in privacy calculus: The case of location-based services," Journal of Management Information Systems, vol. 26, pp. 135-174, 2009.

[52] H. Xu, T. Dinev, J. Smith, and P. Hart, "Information privacy concerns: Linking individual perceptions with institutional privacy assurances," Journal of the Association for Information Systems, vol. 12, pp. 798824, 2011.

[53] V. Venkatesh, S. Brown, and H. Bala, "Bridging the qualitative-quantitative divide: Guidelines For conducting mixed methods research in information systems," MIS Quarterly, vol. 37, p. 21, 2013. https://electricvehiclecouncil.com.au/wp- 